\title{
Grain Deformation Processes in Porous Quartz Sandstones - Insight from the Clusters of Cataclastic Deformation Bands
}

\author{
Sven Philit ${ }^{1}$, Roger Soliva ${ }^{1}$, Gregory Ballas $^{2}$, Haakon Fossen ${ }^{3}$ \\ ${ }^{1}$ Géosciences Montpellier - Université de Montpellier, France \\ ${ }^{2}$ Centre de Bretagne - Ifremer (Brest), France \\ ${ }^{3}$ Department of Earth Science - University of Bergen, and Instituto de Geociências - Universidade de São Paulo, Brazil
}

\begin{abstract}
Porous sandstones represent classical reservoirs for water or hydrocarbons. Deformation in such granular material is due to tectonic events and occurs through the process of cataclasis, implying the crushing of the grains to a diversity of smaller clasts. Cataclasis is generally accompanied by porosity and permeability decrease. Although it is known that cataclastic deformation localizes to form individual bands and clusters of bands, the parameters controlling the distribution of this deformation were not well understood until recently. We used scanline measurements to show a favoured localization and clustering of the deformation on the case of normal-fault stress regime and potentially in strike-slip fault regime. The reverse regime favours the formation of distributed networks of conjugate deformation bands. At the scale of a cluster, field data reveals that the minimum modal grain size value of the host sandstone(s) controls the band density. Finally, microscopic cathodoluminescence analysis reveals enhanced quartz cementation for high degree of cataclasis. Hence, because band clustering, high degree of cataclasis and band cementation are favoured in normal-fault stress regime, tectonic extension appears to be favourable conditions for the formation of efficient barriers to fluid-flow in porous sandstone reservoirs.
\end{abstract}

\section{Introduction}

Clusters of cataclastic deformation bands (CDB clusters) (Fig. 1) are natural geological objects originating from the deformation of porous sandstones, which are granular materials. They are a specific type of strain localization features since they locally accommodate the deformation (shear displacement), but do not necessarily develop discrete slip surface [1]-[3]. These structures consist of a cluster of discrete bands, each with a thickness of $0.5-5 \mathrm{~mm}$ and more densely distributed than in the adjacent sandstone. The CDB clusters are up to a few tens of centimetres wide and their lateral extent ranges from tens to hundreds of metres; they can be relaying over distances of several kilometres (e.g. near Goblin Valley State Park, Utah, USA).

The main process of deformation in porous sandstones is cataclasis. This process consists of a brittle deformation implying grain powdering by rolling, flaking and crushing due to stress concentrations at grain contacts induced by shear and compression [4]-[6]. The process of cataclasis mostly yields compactant structures and can be considered as a ductile deformation at macroscopic scale [7].

Because of porosity and permeability loss during deformation, CDB clusters are likely to affect fluid flow in reservoir settings (permeability reduction up to 6 orders of magnitudes - e.g. [8]). Hence, we think it is important to understand their internal structure and their associated deformation processes in order to understand their resulting sealing vs. draining property. In order to address these issues, we study the distribution of the cataclastic deformation and the structures of the CDB clusters with respect to the following parameters: (1) tectonic regime, (2) grain size of the host sandstone, and (3) cementation.

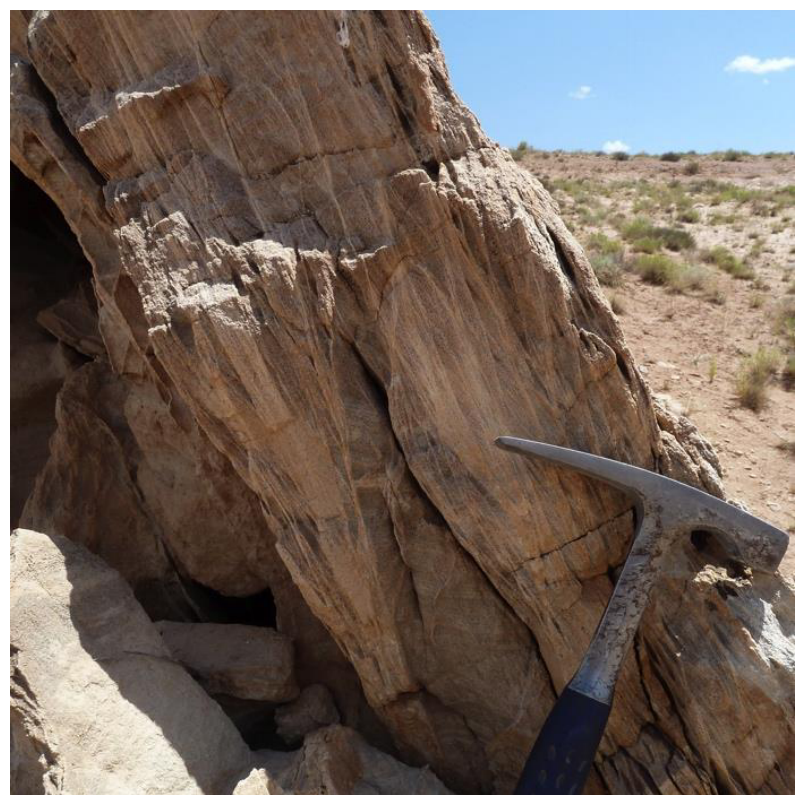

Figure 1. Example of CDB cluster resulting from the localization of deformation in porous sandstones. 


\section{Results}

\subsection{Distribution of the deformation}

The distribution of deformation at the macroscale was measured by counting the number of bands per metres along scanlines oriented in the direction of maximum extension in the case of normal Andersonian regimes, in the direction of maximum shortening in thrust regimes, and normal to the deformation in strike-slip regimes. Band spatial distribution is represented by the cluster factor (see [2] for reference), which is a standard deviation type function allowing to quantify to what extent bands are clustered (high value) or pervasively distributed (low value). These data come from a total of 73 deformation band sets formed in various sandstones (medium sands to fine gravel), various tectonic stress regimes (normal, thrust or strike-slip), and different burial depths $(0.3-2.5 \mathrm{~km})$ [9].

In the normal-fault regime, the deformation consists of Shear Bands and/or Compactional Shear Bands localised as conjugate sets of CDB clusters (9-162 bands/m, Fig. 2), sometimes including a slip surface (fault). Each band typically absorbs a centimetre- to decimetre- displacement.

In the thrust-fault regime, the deformation consists of a network of conjugate Shear-Enhanced Compaction Bands and Compactional Shear Bands distributed from a few centimetres to tens of centimetres apart (6-67 bands/m, Fig. 2) and are extensively distributed at the outcrop (distributed over a zone of up to hundreds of metres). Each band typically absorbs a few millimetres to a few centimetres of shear displacement.

In the strike-slip-fault regime, based on the only 2 studied exposures, the deformation consists of Compactional Shear Bands to Shear Bands localising as CDB clusters (22 and 112 bands/m, Fig. 2).

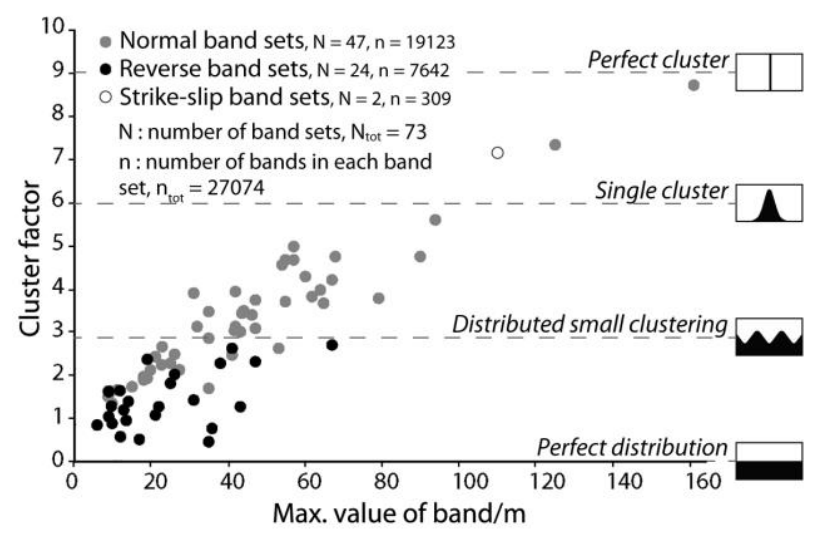

Figure 2. Graph illustrating the geometry of the cataclastic deformation as a function of tectonic regimes in terms of distribution (cluster factor) and band density (Max value of band $/ \mathrm{m}$ ), modified after [9])

As displayed in Fig. 2, normal and strike-slip cataclastic deformation have high cluster factors (1.48.8), implying strong clustering ( 0 representing a perfect even pervasive distribution, and 9 , closing to a perfect CDB clusters). Thrust-fault cataclastic deformation has low cluster factors (0.4-2.8).

\subsection{Intra-cluster deformation density}

At the scale of the CDB clusters, we measure the deformation by counting the cumulated thickness of bands (mm precision) in the thickness of clusters from seven outcrops formed in different tectonic regimes, at different burial depths, and in host sandstones of variable granulometry (see properties in Tab. 1).

For a given cluster, we repeated the measurement 17 to 60 times on a distance $\mathrm{N}$ of several metres along the cluster to validate the accuracy of our data. We represent the density of deformation as the ratio $\left(\mathrm{r}_{\text {band }}\right)$ of cumulated thickness of bands divided by the cluster thickness. The burial of the formation at the time of deformation was obtained in the literature; the granulometry was obtained through laser diffraction analysis.

Table 1. Properties of the deformed granular sandstone and their associated deformation density

\begin{tabular}{|c|c|c|c|c|c|c|}
\hline Site & $\begin{array}{l}\text { Tectonic } \\
\text { Regime }\end{array}$ & $\begin{array}{c}\text { Burial } \\
\text { (m) }\end{array}$ & $\begin{array}{c}\text { Grain } \\
\text { Size }\end{array}$ & $\begin{array}{c}\text { Modal } \\
\text { values } \\
(\mu \mathrm{m})\end{array}$ & $\begin{array}{c}\text { Min } \\
\text { modal } \\
\text { value } \\
(\mu \mathrm{m}) \\
\end{array}$ & $\begin{array}{c}\text { Cluster } \\
\boldsymbol{r}_{\text {band }}\end{array}$ \\
\hline Cum & Normal & $\begin{array}{l}100- \\
400\end{array}$ & Medium & 0.37 & 0.37 & 0.40 \\
\hline $\mathrm{GV}$ & Normal & $\begin{array}{l}1000- \\
2000\end{array}$ & $\begin{array}{l}\text { Fine to } \\
\text { Medium }\end{array}$ & $\begin{array}{c}0.20 \\
0.28\end{array}$ & 0.20 & 0.26 \\
\hline Bon & Normal & $\begin{array}{c}300- \\
600\end{array}$ & $\begin{array}{l}\text { Fine to } \\
\text { Coarse }\end{array}$ & $\begin{array}{l}0.21 \\
0.41 \\
0.75\end{array}$ & 0.21 & 0.11 \\
\hline BG & Thrust & $\begin{array}{l}500- \\
1500 \\
\end{array}$ & Medium & 0.29 & 0.29 & 0.19 \\
\hline Bla & Thrust & $\begin{array}{l}100- \\
800\end{array}$ & Medium & 0.37 & 0.37 & 0.41 \\
\hline Bed & S-S & $\begin{array}{l}50- \\
200\end{array}$ & Medium & 0.29 & 0.29 & 0.35 \\
\hline StM & S-S & $\begin{array}{c}300- \\
600\end{array}$ & $\begin{array}{l}\text { Medium } \\
\text { to } \\
\text { Coarse }\end{array}$ & $\begin{array}{l}0.37 \\
0.78\end{array}$ & 0.37 & 0.35 \\
\hline
\end{tabular}

In the normal regime, the deformation density $r_{\text {band }}$ ranges from 0.11 (Bon) to $0.26(\mathrm{GV})$ to 0.40 (Cum). The measured $r_{\text {band }}$ for the cluster formed in the thrust regime (much rarer) equals 0.19 at $\mathrm{BG}$ and 0.41 at Bla. The measured $r_{\text {band }}$ for the clusters formed in strike slip (rare) equals 0.35 for both Bed and StM. In Fig. 3, we plotted the deformation density as a function of most finegrained host sandstone.

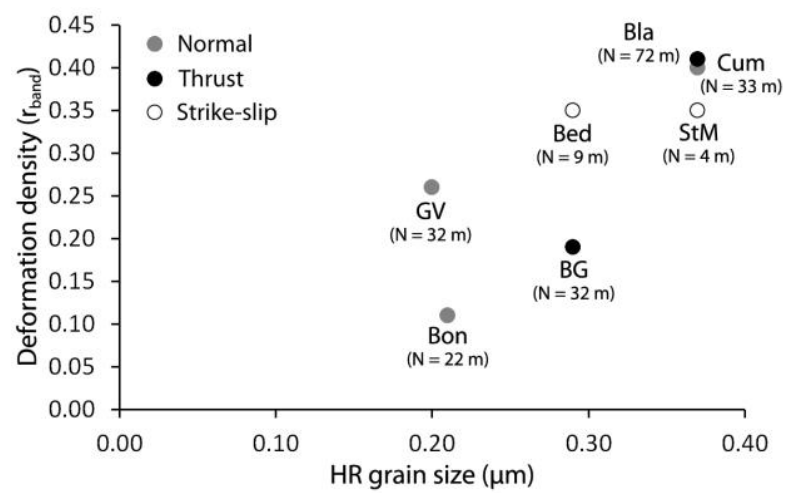

Figure 3. Graph displaying the relationship between the deformation density in the clusters and the modal grain size of the most fine-grained host sandstone, if several sandstones were displaced against each other. 


\subsection{Cementation in cataclastic textures}

In clean sandstones, CDB clusters often show quartz cementation [10], [11] under the form of 1-10s of $\mu \mathrm{m}$ coatings around the clasts (Fig. 4). This cementation is observed into $\mathrm{CDB}$ clusters formed in sand series having been buried to $400 \mathrm{~m}$ or more. We observe particularly well cemented clusters at Bédoin, Provence (France) in clean arenite sandstone buried at a maximum depth of $800 \mathrm{~m}$. The alteration profile at this site demonstrates an aquifer environment at the time of deformation.

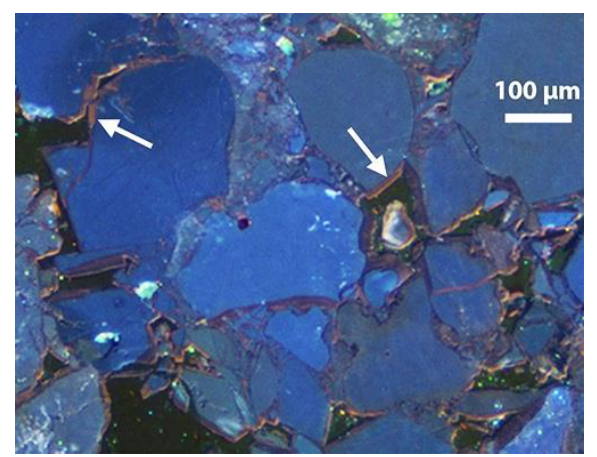

Figure 4. Imaging in Cathodoluminescence (CL) of the coating of quartz cements around the clasts (arrows) in partially cemented Crush microbreccia.

At the macroscopic scale, a census of the deformation and cementation in the thickness of the cluster and on a distance of $9 \mathrm{~m}$ along-strike the cluster indicates that cemented cataclastic bands account for at least $19 \%$ of the cluster thickness. These structures are variably connecting alongside the cluster depending on the distribution and orientation of the bands.

We undertake Cathodoluminescence microscopy (CL) to assess the degree of cataclasis and the relative amount of cement in several parts of an $80 \mathrm{~cm}$ wide CDB cluster. The cataclasis is considered as the fraction of rock occupied by clasts; we consider clasts as the fragments of sand grains whose Ferret diameter is lower than $10 \%$ of the modal grain diameter of the host sandstone. We use the classification proposed by Sibson [12] to designate different degrees of cataclasis. We use the Intergranular Volume (IGV) [13] to qualify the porosity of the rock previous to cementation.
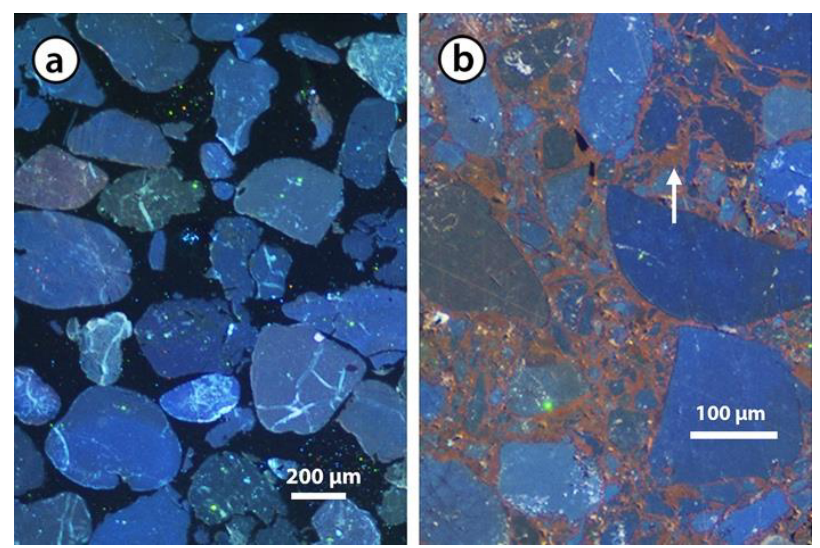

Figure 5. (a) Uncemented host sand in CL; (b) highly cemented protocataclasite in CL.

In the host sand next to the cluster, porosity equals $31 \%$ and no cement is observed (Fig. 5a). The parts of the cluster where cataclasis represents $9 \%$ of the rock correspond to uncemented to partially cemented crush microbreccia with IGV of $22 \%$ (Fig. 4). In the partially cemented crush microbreccia, the resulting porosity can be as low as $12 \%$. The parts of the cluster where cataclasis represents $30 \%$ of the rock correspond to partially cemented to highly cemented protocataclasite with IGV of $10 \%$ (Fig. 5b). The resulting porosity is estimated to $5 \%$ or lower. The parts of the cluster where cataclasis represents $60 \%$ of the rock correspond to highly cemented cataclasite with $\mathrm{IGV} \leq 5 \%$. The resulting porosity is estimated as lower than $4 \%$. These observations are summarized in Fig. 6.

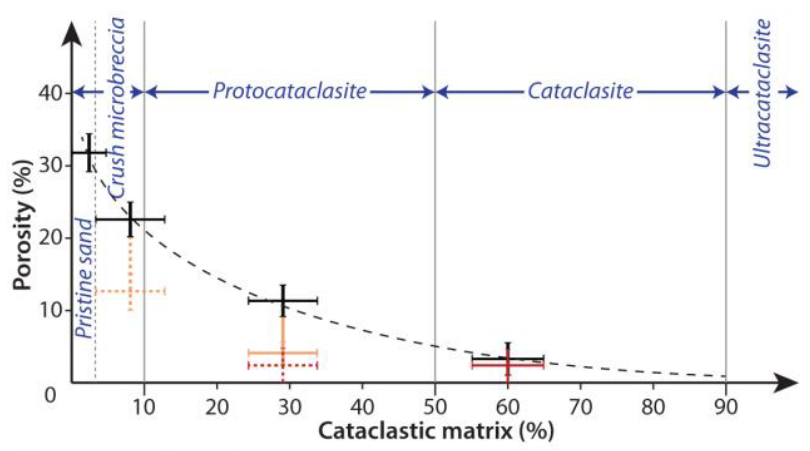

- Uncemented cataclastic microstuctures

H Partially cemented cataclastic microstructures Dashed: Frequent occurences H Highly cemented cataclastic microstructures Solid: Most common occurences Figure 6 . Graph showing the relationship between porosity, degree of cataclasis and degree of cementation.

\section{Concluding discussion}

The data from the scanline measurements shows the clustering of cataclastic shear band in the normal-fault tectonic regime. In the thrust-fault regime, deformation is for the most part widely distributed as conjugate network of individual cataclastic compaction bands. This difference in behaviour could be explained by the different stress paths to which the sandstone was submitted [3]: the normal-fault regime would imply low mean stress and high differential stress leading to localized shear, whereas the thrust-fault regime would induce high mean stress and moderate differential stress and cause distributed deformation. This hypothesis is consistent with laboratory mechanical tests (e.g. [14]).

At the scale of the cluster thickness, no direct relation between deformation density $\left(\mathrm{r}_{\text {band }}\right)$ and tectonic regime or the burial depth is observed for the studied clusters. However, our data suggest a positive correlation between deformation density and the modal grain size of the most fine-grained HR (if two different sandstones displaced against each other): the higher the sandstone grain size, the higher the deformation density. We hypothesize that, for comparable sorting, high shear strain density could be favoured by more grain contacts (more resistance to compaction) in fine sandstones than the medium to coarse sandstones [4]. This is consistent with brittle-ductile transition occurring for high mean stress in fine sandstones, then favouring strain localisation under coulomb-type shear behaviour for low confinement in such material (e.g. [14-15]). Although 
the grain size seems to have a significant impact on the morphology of the cluster (e.g. the density of the deformation as we just showed, or the cluster thickness [16]), other properties such as the grain sorting or the grain shape of the grains may also influence the density of deformation bands in a cluster. The analysis of the deformation density in the cluster should be undertaken on more sites to strengthen our conclusion and to better understand the main control of the most fine-grained HR.

Our study of the influence of cataclasis on the diagenesis shows that increasing cataclasis favours quartz cementation. Consequently, the low porosity of the cataclastic structures is further reduced and the permeability across the clusters potentially decreased, even at shallow burial. As argued by several authors [17-21], cementation would be promoted by the large amount of fresh-reactional quartz surfaces (nucleation discontinuities) in contact with the nourishing fluid. In particular, it is suggested that the high silica concentration responsible for this cementation may be released and reprecipitated during the cataclastic deformation, implying an immediate self-sealing of the structure [22]. We note that the nucleation of silica may be possible if no oxide (or clay) coats the reactional surface, as they may inhibit quartz precipitation [23], [24]. Nevertheless, these conclusions are important because although well-known at depths $>1.5 \mathrm{~km}$ [18], [25], [20], quartz diagenesis at low burial was rarely reported (e.g. [26]).

We note that further microscopic study of the deformation could be completed by micro-mechanical analysis through Discrete Element Modelling (DEM). Over the past ten years, DEM studies have shown efficient grain fragmentation modelling, using welldefined bond properties at grain contacts (contact force, friction and cohesion). In particular, the geometry, the clast properties and the dilatancy and softening behaviours of shear bands can be anticipated as functions of the loading conditions, the cementation and the sample size of the modelled sandstones (e.g. [27-29]).

Since CDB clusters extend for $10 \mathrm{~s}$ to $100 \mathrm{~s}$ of metres, they are potential barriers or baffles to fluid flow in reservoir settings. This work actually suggests that the link between the tectonic regime and the degree of cataclasis must be studied carefully as we showed that intense cataclasis can generate high permeability decrease both through mechanical and chemical (cementation) processes. Preliminary results seem to show that localizing normal fault-stress regime generate more cataclasis through more shearing. Also, the grain size of the host sandstone could influence the barrier efficiency of a band cluster since it seems to affect the deformation density in clusters.

\section{References}

1. H. Fossen, R. A. Schultz, Z. K. Shipton, and K. Mair, J. Geol. Soc. 164, 4 (2007)

2. C. A. J. Wibberley, J.-P. Petit, and T. Rives, Geol. Soc. Lond. Spec. Publ. 289, 1 (2007)
3. R. Soliva, R. A. Schultz, G. Ballas, A. Taboada, C. Wibberley, E. Saillet, A. Benedicto, J. Struct. Geol. 49, pp. 50-63 (2013).

4. J. J. Gallagher Jr, M. Friedman, J. Handin, and G. M. Sowers, Tectonophysics 21, 3 (1974)

5. A. Aydin and A. M. Johnson, Pure Appl. Geophys. 116, 4-5 (1978)

6. M. Antonellini and A. Aydin, AAPG Bull. 78, 3 (1994)

7. M. Friedman and J. M. Logan, Geol. Soc. Am. Bull. 84, 4 (1973)

8. G. Ballas, H. Fossen, and R. Soliva, J. Struct. Geol. 76, pp. 1-21 (2015)

9. R. Soliva, G. Ballas, H. Fossen, and S. Philit, Geology 44, 6 (2016)

10. N. L. Watts, Mar. Pet. Geol. 4, 4 (1987)

11. Q. J. Fisher and R. J. Knipe, Mar. Pet. Geol. 18, 10 (2000)

12. R. H. Sibson, J. Geol. Soc. 133, 3 (1977)

13. S. T. Paxton, J. O. Szabo, J. M. Ajdukiewicz, and R. E. Klimentidis, AAPG Bull. 86, 12 (2002)

14. T. Wong and P. Baud, J. Struct. Geol. 44, pp. 2553, (2012)

15. E. H. Rutter and C. T. Glover, J. Struct. Geol. 44, pp. 129-140, (2012)

16. H. Fossen, R. Soliva, G. Ballas, B. Trzaskos, C. Cavalcante, and R. A. Schultz, J. Geol. Soc., (to be published)

17. M. Canals and J. D. Meunier, Geochim. Cosmochim. Acta 59, 4 (1995)

18. Q. J. Fisher and R. J. Knipe, Geol. Soc. Lond. Spec. Publ. 147, 1 (1998)

19. Q. J. Fisher, R. J. Knipe, and R. H. Worden, in Quartz Cementation in Sandstones, Blackwell Science., R. H. Worden and S. Morad, Eds. International Association of Sedimentologists Special Publication 29, pp. 129-146 (2000)

20. R. H. Lander, R. E. Larese, and L. M. Bonnell, AAPG Bull. 92, 11 (2008)

21. R. T. Williams, J. R. Farver, C. M. Onasch, and D. F. Winslow, J. Struct. Geol. 74, pp. 24-30 (2015)

22. B. T. Ngwenya, S. C. Elphick, I. G. Main, and G. B. Shimmield, Earth Planet. Sci. Lett., 183 (2000)

23. E. F. McBride, "Quartz cement in sandstones: a review," Earth-Sci. Rev., 26, 1-3 1989.

24. S. N. Ehrenberg, AAPG Bull. 77, 7 (1993)

25. O. Walderhaug, AAPG Bull. 84, 1-2 (2000)

26. K. L. Milliken, M. H. Reed, and S. E. Laubach, in Faults, fluid flow, and petroleum traps, R. Sorkhabi and Y. Tsuji, Eds. pp. 237-249 (2005)

27. Y. H. Wang and S. C. Leung, J. Geotech. Geoenvironmental Eng. 134, 7 (2008)

28. M. Jiang, H. Chen, and G. B. Crosta, Int. J. Rock Mech. Min. Sci. 78, pp. 175-189 (2015)

29. G. Pál, Z. Jánosi, F. Kun, and I. G. Main, Phys. Rev. E 94, 5 (2016) 